\title{
LEARNING MECHANICS OF MATERIALS BY DOING MODELS
}

\author{
I. Montava Belda, E. Juliá Sanchis, J.M. Gadea Borrell, J. Segura Alcaraz \\ Universitat Politècnica de València (SPAIN)
}

\begin{abstract}
Mechanics of Materials is a discipline taught to the second-year students in the Bachelor Degree of Mechanical Engineering at Universitat Politècnica de València, Alcoi Campus. The teaching-learning process is focused on three main aspects: theory, practice, and numerical simulations. There are several experiments designed to better understand the mechanical behaviour of the materials that are present in buildings and machines. This paper explains the application of another hands-on methodology that has been included in the course. It consists of completing the process by constructing or prototyping scale models which help the students to understand how the structures work in real life. The results of the experience allow us to consider that learning by doing has supposed a significant step in the comprehension of the Mechanics of Materials and the students have showed a positive attitude towards this activity. Not only by constructing models, but the fact that their construction is blended with other active methodologies, contribute to enhance the motivation in learning the subject.
\end{abstract}

Keywords: Mechanics of Materials, Learning by doing, Scale models, Prototyping.

\section{INTRODUCTION}

Higher institutions all around the world are promoting active methodologies to teach technical courses by means of different strategies as Project-based Learning [1], [2] [3]. To adapt a course from a passive methodology to an active learning strategy, we present the particular case of the course Mechanics of Materials in the Bachelor Degree of Mechanical Engineering at Universitat Politècnica de València, Alcoi Campus.

Mechanics of Materials is considered one of the core subjects in the studies programmes of Mechanical Engineering and it is considered by students, in many occasions, one of the most difficult courses [4]. In fact, lots of lecturers are concerned about how to balance the difficulty of the course and the motivation of the students.

This communication presents the activity that has been included in the course "Mechanics of Materials" which contributes to enhance the motivation of the students. In our case, the Mechanics of Materials course is divided into two semester courses: Mechanics of Materials I (4,5 credits) and Mechanics of Materials II ( 6 credits). Both courses are taught in second year and the content is shown in Table 1:

Table 1. Contents of the Mechanics of Materials I and II courses.

\begin{tabular}{c|c}
\hline \hline Mechanics of Materials I (4,5 credits) & Mechanics of Materials II (6 credits) \\
\hline $\begin{array}{c}\text { Introduction to Elasticity and } \\
\text { Mechanics of Materials }\end{array}$ & $\begin{array}{c}\text { Analysis and design of statically } \\
\text { determinate and indeterminate systems }\end{array}$ \\
\hline Force diagrams and moments in straight elements & Energy methods \\
\hline Axial stress & Bidimensional elasticity \\
\hline Simple shear stress & Failure crietria \\
\hline Torsion & Experimental methods \\
\hline Bending & Advanced problems \\
\hline Buckling & \\
\hline Combined loading & \\
\hline \hline
\end{tabular}

It has been demonstrated in many studies that the hands-on methodologies [5] help the students to understand the concepts and procedures of any subject much better than only offering them theoretical content. 
Regarding learning-by-doing methodology, in the last recent years the Universitat Politècnica de València has included thirteen competences to be evaluated along the studies (Table 2). It is expected that at the end of the studies, the students will achieve those competences. In the particular case of the courses of Mechanics of Materials, the transverse competence that is included as part of the assessment is CT-06: Teamwork and leadership.

Table 2. Transverse Competences at Universitat Politècnica de València.

\begin{tabular}{c}
\hline Transverse Competences (CT) \\
\hline CT-01 - Comprehension and integration \\
\hline CT-02 - Application and practical thinking \\
\hline CT-03 - Analysis and problem-solving \\
\hline CT-04 - Innovation, creativity and entrepreneurship \\
\hline CT-05 - Design and project \\
\hline CT-06 - Teamwork and leadership \\
\hline CT-08 - Effective communication \\
\hline CT-09 - Critical thinking \\
\hline CT-10 - Knowledge of contemporary problems \\
CT-11 - Lifelong learning \\
\hline CT-12 - Planning and time management \\
CT-13 - Specific instrumental
\end{tabular}

With the new strategy of "learning-by-doing", the creativity of the student is valued considerably when facing a challenge related to a real project. By improving the structural element, a project related to the Transversal Competence CT-04 (Innovation, creativity and entrepreneurship) is proposed, which is required in the curricula of our future engineers by allowing the students to redesign the problems observed in the structural analysis of the urban element and propose novel solutions to improve it. The creativity of the students, their ability to implement technological concepts and to work in a team are assessed with this activity.

\section{METHODOLOGY}

In the laboratory of the Department of Continuous Medium Mechanics and Theory of Structures at the Campus of Alcoi, different experiments have been designed to adapt the educational methodology in order to increase the active learning of the students by means of continuous assessment.

In the previous system of teaching Mechanics of Materials, the credits/hours dedicated to practical classes were presented in the following way [6]:

1 An experimental set-up is explained to the group.

2 The group is divided into small groups, up to 4 students.

3 The groups have different tasks: experimental, analytical and numerical simulation.

4 At the end of the class, the students deliver the completed report.

Figure 1 shows some of the experimental set-ups in the laboratory used for the practical sessions: 

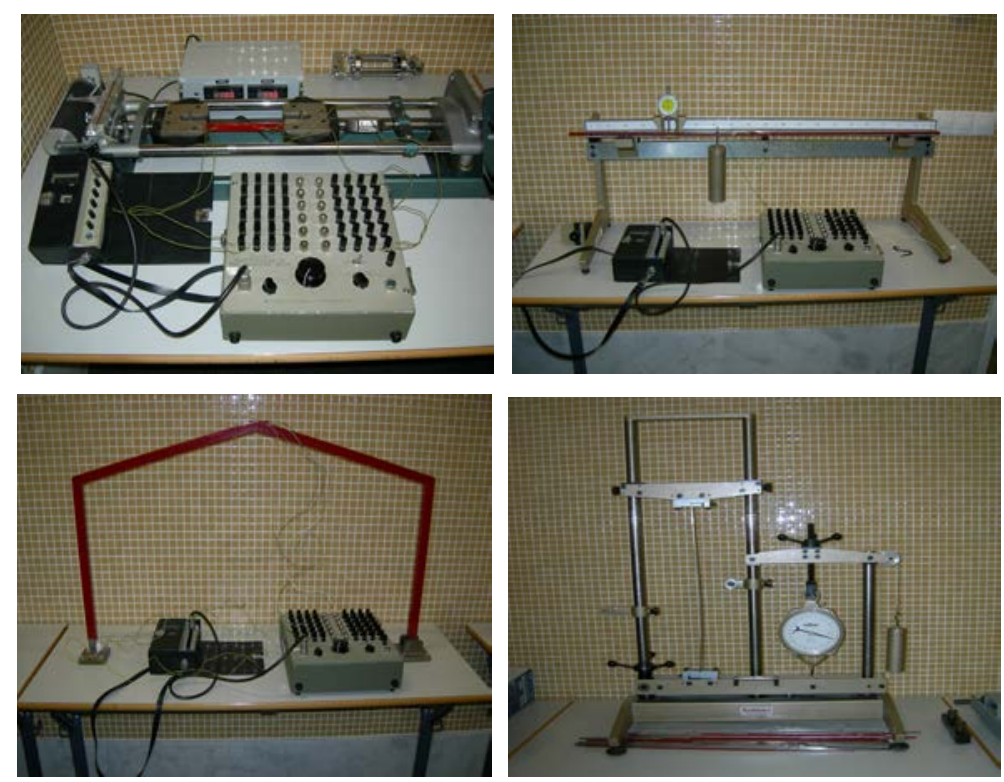

Figure 1. Experimental set-ups for practical classes.

In the new system of teaching, the "learning-by-doing" strategy has been included in the course of Mechanics of Materials, so that a task is proposed to the group in the following way:

1 Small groups, up to 3 students, choose a particular type of structure for its structural analysis.

2 The students must study analytically the mechanical behavior of the components of the structure.

3 They must build a scale model according to the dimensions determined in step 2.

4 They have to explain and present their models to the whole group answering the questions asked by the other students and the teacher.

Figure 2 shows some models constructed by students.

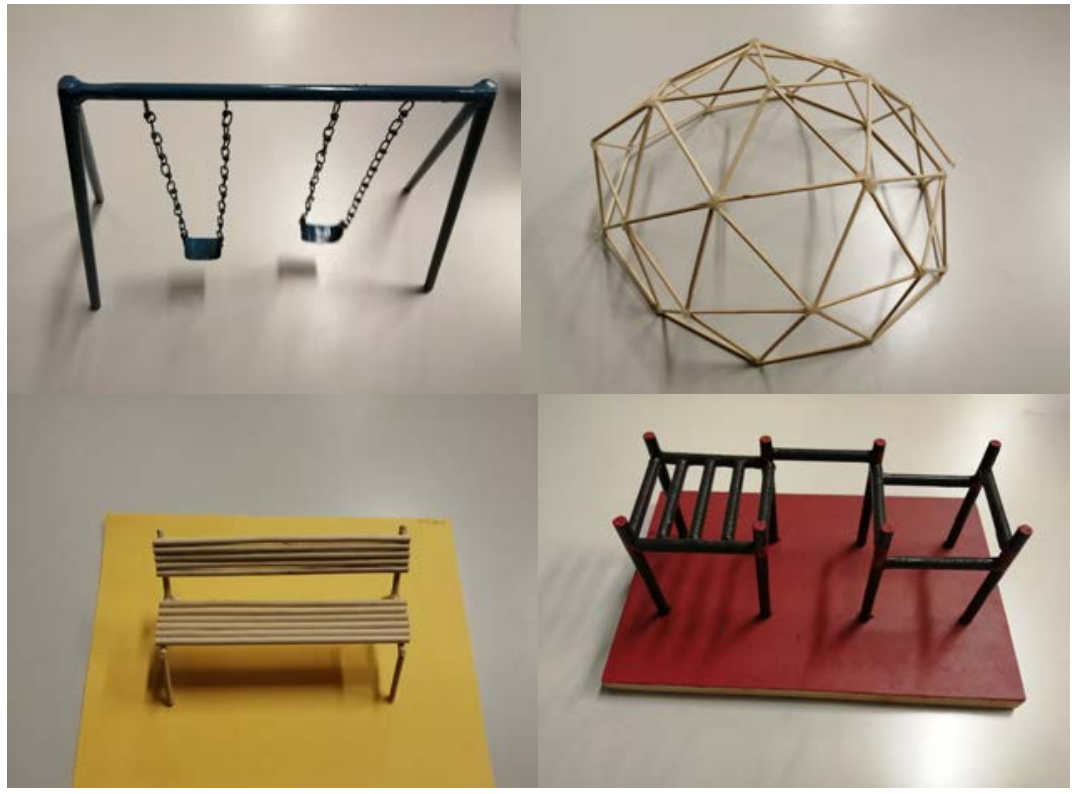

Figure 2. Models constructed by students.

The evaluation, which will consist of three parts, is explained at the beginning of the course with the following instructions:

1 Part 1. Three exams (60\%; $20 \%$ each). 
The minimum grade of the average of the 3 tests must be equal to or greater than 4 points out of 10.

2 Part 2. Laboratory classes (20\% of the total value).

There will be six laboratory classes that will allow to check the concepts learned in theory classes by means of experimental set-ups.

3 Part 3. Group work ( $20 \%$ of the total value).

A work is proposed to teams, up to 3 students, on the analysis of the structure of an element related to mechanical engineering, for example urban furniture (canopies, benches, swings, signs, wastebaskets, bicycle parking, etc). A modification or improvement of the urban furniture analysed has to be proposed by the team.

It is divided into 5 stages, which will allow to complete the process of analysis, calculation and design of a structural element:

- Stage 1. Preliminary project. Study of the structural element. Photos, dimensions, improvements, new materials, location, plan and section.

- Stage 2. Structural design. Structure geometry, modelling, materials and their mechanical properties, loads, nodes and supports, resistance limitations and deformations.

- Stage 3. Structural calculation. Pre-dimensioning and calculation with a computer program.

- Stage 4. Final project delivery. Resizing, structural plans, final design, model.

- Stage 5. Presentation. Each group will present their project to the rest of the class (up to nine minutes). Each student participating in three minutes.

\section{RESULTS}

The inclusion of the "learning-by-doing" task has demonstrated that the knowledge acquisition improves due to the better understanding of the static structural behavior of a particular structure when it has to be constructed. It can be said that the activity is conducted to achieve the two following objectives:

- To work in a team, since the students are distributed into small working groups.

- To understand the main concepts applied to experimental procedures.

To reach these two objectives, the activity has been organised by considering these three aspects:

a) Identification of objectives.

b) Preparation of instructions.

c) Estimation of the time to do the activity.

Figure 3 shows in a graph the interaction between "Concepts", "Experimental Procedures" and "Learning-by-doing", which results in a better knowledge acquisition.

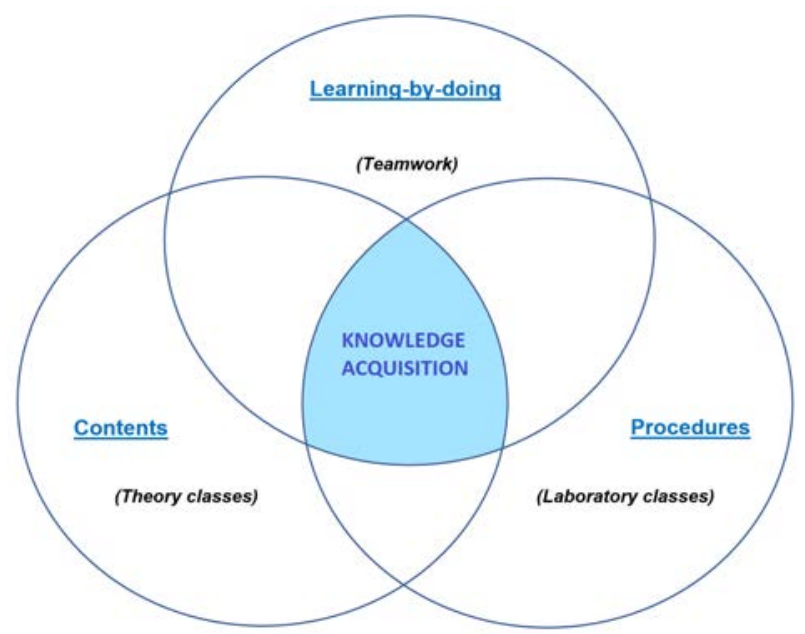

Figure 3. Interaction between "Concepts", "Experimental Procedures" and "Learning-by-doing". 
Once the activity has been developed by the students, it has to be assessed by the lecturer. A number of indicators are used to evaluate the task (Table 3 ).

Table 3. Indicators to evaluate the task.

\begin{tabular}{l|l}
\hline \multicolumn{1}{c|}{ INDICATOR } & \multicolumn{1}{c}{ EVIDENCE } \\
\hline Use of the content learned in class. & $\begin{array}{l}\text { Use appropriately the concepts and the analytical methods taught } \\
\text { in class. }\end{array}$ \\
\hline $\begin{array}{l}\text { The model transmits relevant information } \\
\text { about their structural behaviour. }\end{array}$ & $\begin{array}{l}\text { It exposes clearly how the structural components of the model } \\
\text { work, according to the axial, shear, torsion and bending stresses. }\end{array}$ \\
\hline $\begin{array}{l}\text { The presentation of the activity is properly } \\
\text { prepared. }\end{array}$ & $\begin{array}{l}\text { Explains the main ideas about the model and its connection with } \\
\text { the real product static structural behavior. }\end{array}$ \\
\hline Accept the team's objectives. & $\begin{array}{l}\text { Do the assigned tasks and respects the other members' ideas } \\
\text { about the design and construction of the model. }\end{array}$ \\
\hline \hline
\end{tabular}

The results have been very satisfactory. With this activity, the students have demonstrated the knowledge acquired throughout the laboratory and theory classes by means of a practical work. It is essential to highlight the improvement in their motivation when working on a real project that they can assimilate as a future job in their professional life.

The choice of urban furniture allows to obtain a great variety of structural elements that are easy to recognize and allow to acquire knowledge not only from their own project, but from the other classmates.

When working in a team the students face the advantages and drawbacks of teamwork, dealing with internal problems that they have to solve.

At the end of the course, a questionnaire related to this task is sent to the students:

1 Do you think your academic performance has improved? (YES/NO)

2 Do you consider that your motivation in the contents of the course has increased? (YES/NO)

3 Does it promote teamwork and collaboration? (YES/NO)

4 Do you think it is better to do the work individually? (YES/NO)

5 Do you consider that you have become aware of your own learning? (YES/NO)

6 Suggestions to improve the subject for the next academic year. (OPEN ANSWER)

7 Suggestions to improve the learning-by-doing task for the next academic year. (OPEN ANSWER)

\section{CONCLUSIONS}

Nowadays, the active methodologies that the new education systems are demanding have contributed to the inclusion of the "learning-by-doing" strategy in the course of Mechanics of Materials.

The activity has been positively evaluated by the students, who are being used to learn through active strategies. With this activity, the Teamwork and Leadership competence has been included in the gradebook of the course.

The creativity of the students, their ability to implement technological elements and to work in a team have been considerably assessed. Learning by doing their own project has resulted in better understanding the concepts of the course Mechanics of Materials.

Apart from enhancing the teamwork among the students, it has had a significant contribution to the understanding of the static structural behaviour of the structures represented by the models.

It is also worth mentioning that this learning-by-doing activity is easily transferable to other disciplines in the field of engineering, which encourage the participants to continue applying this active strategy in other subjects. 


\section{REFERENCES}

[1] M. M. Pastor et al., "Learning in engineering through design, construction, analysis and experimentation," Int. J. Eng. Educ., vol. 35, no. 1, 2018.

[2] I. D. L. Ríos, A. Cazorla, J. M. Díaz-Puente, and J. L. Yagüe, "Project-based learning in engineering higher education: Two decades of teaching competences in real environments," in Procedia - Social and Behavioral Sciences, 2010, vol. 2, no. 2.

[3] T. Joyce, I. Evans, W. Pallan, and C. Hopkins, "A hands-on project-based mechanical engineering design module focusing on sustainability," Eng. Educ., vol. 8, no. 1, 2013.

[4] G. N. Saunders-Smits and J. De Vries, "Learning by doing: An innovative laboratory exercise to enhance the understanding of thin-walled Mechanics of Materials," in ASEE Annual Conference and Exposition, Conference Proceedings, 2005.

[5] S. Niiranen, "Supporting the development of students' technological understanding in craft and technology education via the learning-by-doing approach," Int. J. Technol. Des. Educ., vol. 31, no. 1, 2021.

[6] J.M. Gadea Borrell, J. Segura Alcaraz, E. Juliá Sanchis. "Design of Experiments in a Laboratory of Mechanics of Engineering Materials,", EDULEARN09 Proceedings, International Conference on Education and New Learning Technologies, ISBN: 978-84-612-9801-3, p. 870-877, 2009. 